\title{
Pakistan's Exchange Rate Policy: An Econometric Investigation
}

\author{
MOHAMMAD AHMED
}

\begin{abstract}
This paper examines empirical determinants of the Pakistani rupee exchange rate since the advent of the managed float in 1982. The behaviour of the nominal exchange rate results from policy intervention carried out by the monetary authorities. Various testable hypotheses are developed in order to discern the factor(s) which can be the determinants of the nominal rupee exchange rate. In the short run, authorities follow a contingent policy rule with respect to movements of the U. S. dollar against the SDR. Based on vector autoregression techniques, the error correction model is employed to check the consistency of the short-run adjustment process, given the authorities' longrun target rupee value. The 'revealed' policy is to partly offset the inflation differential between Pakistan and its major trading partners. Under plausible conditions, the burden of adjustment and recessionary conditions are likely to occur in the Pakistani export sector.
\end{abstract}

\section{INTRODUCTION}

The aim of this paper is to study the determinants of the nominal rupee exchange rate in Pakistan since the advent of the managed float of the Pakistani rupee in January, 1982. Prior to this period, the Pakistani rupee was pegged to the U. S. dollar. Qureshi (1978) calculates that due to greater inflation in Pakistan relative to other countries (32.4 percent for the period between December, 1973 and April, 1978), the rupee was found to be overvalued to the extent of 31.2 percent at its official rate of exchange. In the earlier part of the 1980s, the Reagan administration in the United States undertook fiscal expansion with tight monetary policy measures, as a result of which the interest rates in the United States shot up to an unprecedented level. Consequently, the dollar appreciated against most of the other major international currencies, leading to a revaluation of the Pakistani rupee. The calculations of Malik and Rizavi (1982) show that between December, 1980 and

Mohammad Ahmed is Senior Research Economist, National Development Finance Corporation, Karachi, currently studying for a Ph. D. at the University of Sussex, England.

Author's Note: I am grateful to Professors Alasdair Smith, Mike Sumner, and Adrian Wood of the University of Sussex and two anonymous referees of this Journal for their helpful comments on an earlier draft of this paper. Incisive comments by Andrew Newell of the University of Sussex did much to improve this paper. Needless to say, I alone am responsible for any errors and omissions. 
December, 1981, the Pakistani rupee appreciated substantially, for example, by 22.9 percent against the pound sterling, and by 25.12 percent against the French Franc. In overall terms, the nominal (trade-weighted) appreciation of the Pakistani rupee was 7.94 percent against ten international currencies. The above revaluation of the rupee had adverse effects on the Pakistani exports to non-dollar area; it made imports cheaper in Pakistan (which, to an extent, helped in containing inflationary pressures) and became a disincentive for foreign exchange remittances of overseas Pakistanis. Therefore, a decision was made to delink the Pakistani rupee from the U. S. dollar with the proviso that the dollar would still retain its position as an intervention/vehicle currency. On delinking from the U. S. dollar in January, 1982, the rupee was depreciated by 4 percent and the depreciation between January, 1982 and June, 1986 has been 39 percent (on the basis of average monthly exchange rates). Consequently, all the other international currencies floated against the rupee via international cross rates. However, the official position of the Government of Pakistan (GOP) is that it maintains a managed floating exchange rate of the rupee $v i s-\grave{a}$-vis the U.S. dollar, with reference to an undisclosed basket of currencies of Pakistan's major trading partners.

Since the rupee has been on a managed float, the monetary authorities (i.e., the State Bank of Pakistan - SBP) in Pakistan have intervened in the foreign exchange market with varying frequency in any given month. ${ }^{1}$ In this paper, we seek to investigate and assess the significance of factors which prompt the SBP to announce changes in the rupee parity rate (i.e., short-run movements in the nominal exchange rate). We, then, attempt to identify economic indicators, which in the long run critically affect the movements in the rupee parity rate. The approach adopted is unconventional inasmuch as instead of constructing a partial or a general equilibrium model for the optimal currency peg, in the context of the LDCs [Williamson (1982)], we try to 'guess' the actual rule of the nominal rupee exchange rate management by the SBP.

In Section II, a literature survey, concerning the econometric and exchange rate management issues, is conducted in order to provide a perspective for Section III. In Section III, trend properties of the data are characterized and the error correction mechanism specification employed to form a consistent dynamic policy reaction function. The economic implications of the 'revealed' exchange rate policy are then discussed.

${ }^{1}$ For the period under study, there did not exist a formal foreign exchange market in Pakistan. Foreign capital inflows and outflows were tightly regulased and monitored by the SBP. Apparently, before the banks open for business, the Governor of the SBP decides whether to initiate changes in the rupee parity rate. Therefore, Pakistan's exchange rates are not market-determined. However, there exists a parallel or black market in foreign currencies, in which there does not appear to be a significant divergence between the official and the black market exchange rate. 


\section{SURVEY OF LITERATURE}

The problems of exchange rate management for the LDCs authorities are varied, and include issues such as promotion of exports, economic stability, limiting imported inflation, encouraging foreign investments, etc. [For further discussion, see Gylfason (1986, 1987)]. However, the question of overvaluation of a country's exchange rate with respect to its long-run equilibrium value has significant welfare costs. Without delving too deeply into this issue, it may suffice to point out that a misaligned exchange rate generates incorrect signals to economic agents; and the prospect of an imminent exchange rate realignment generates potential uncertainty in the economy which can lead to an unsustainable pressure on foreign exchange reserves.

\section{1. Econometric Issues}

In the above context, Edwards (1984) makes a pertinent observation. The modern approach suggests that the equilibrium value of the exchange rate can vary through time, whereas under the PPP approach, any deviation from an unchanging equilibrium exchange rate was taken to reflect a disequilibrium exchange rate. Various effects of tarrif policy, terms of trade changes, capital flows, and economic growth on the equilibrium exchange rate can then be analysed. The equilibrium exchange rate itself is defined in terms of a long-run sustainable current account as a fraction of output. Dornbusch (1980) defines the equilibrium real exchange rate as the relative price of tradeables to non-tradeables at which income equates expenditure and both the tradeables and non-tradeables goods markets are in equilibrium. The modern approach to an equilibrium exchange rate determination invalidates the standard linear regression estimation. This can be seen as follows: Suppose, a short-run adjustment mechanism is postulated via the conventional partial adjustment mechanism (PAM). ${ }^{2}$ The partial adjustment process between the (log of the rupee exchange rate $\left(y_{t}\right)$ and the (log of) the U. S. dollar vis-à-vis the SDR exchange rate $\left(x_{\mathfrak{t}}\right)$ is specified as follows (for details, see below):

$$
y_{t}-y_{t-1}=(1-\tau)\left(y_{t}^{*}-y_{t-1}\right)+u_{t} \quad 0 \leq \tau \leq 1
$$

${ }^{2}$ However, the above formulation of the adjustment mechanism is valid when the positive and negative adjustments are equally costly (derived by minimizing the quadratic cost functions). If the authorities are concemed and take into account the fact that additional significant adjustment costs can be imposed on various sectors of the economy by an 'erratic' behaviour of control variable $y_{i}$, then the above specification incorrectly sets the economy-wide adjustment costs at zero. An erratic behaviour of the control variable implies that growth in $y_{t}$ is over and above its underlying trend, i.e., minimizing the quadratic cost functions, where costs are attached only to deviations from trend growth. [Pagan (1985), p. 203] suggests that an inclusion of an intercept term in the PAM would be a simple way of enforcing trend neutrality. 
Formally, we require that the short-run adjustment mechanism achieve a zero steady-state error, given the equilibrium rupee exchange rate value, denoted by $y_{t}^{*}$. We postulate a simple log-linear relationship for the target variable $\left(y_{i}^{*}\right)$ :

$$
y_{t}^{*}=\text { constant }+B x_{t}+\mu x_{t-1}+\varnothing z_{t-i}
$$

where the variable $z$ represents domestic macro-economic variable (see below). Substituting the PAM in the above equation, the equation obtained is:

$$
y_{t}=\text { constant }(1-\tau)+\tau y_{t-1}+B(1-\tau) x_{t}+\mu(1-\tau) x_{t-1}+\emptyset(1-\tau) z_{t-i}+u_{t}
$$

where $y_{t}$ : Defined as the (in logs) price of domestic money in terms of foreign money, i.e., U. S. dollar per Pakistani rupee. A fall in $y_{t}$ is a depreciation of rupee;

$x_{t} \quad$ : U. S. dollar per SDR (in logs); and

$z_{t-i}$ : Fundamental economic variable that is discounted by monetary authorities in the long run (in logs).

In the above equation, the error term $(u)$ is presumed to satisfy the usual classical assumptions of the OLS regression.

The focus of this paper is to model the long-run exchange rate path. The question we wish to consider is the consistency of the short-run adjustment given an equilibrium target path. ${ }^{3}$ Salmon (1982) points out that the use of the partial adjustment process will only achieve the target level $\left(y_{t}^{*}\right)$ if that level is constant in steady-state. If the target path is growing, then the partial adjustment model will lead to non-zero steady-state error and the model will diverge from the target path. Since the equilibrium value of exchange rate can be expected to vary through time, then, in such circumstances, there may potentially be a conflict between the attainment of steady-state properties and relatively non-oscillatory short-run properties in the model [Salmon (1982), p. 622]. Therefore, it could be the case that the estimated (short-run) PAMs exhibits explosive tendencies (i.e., $\tau>1$ ). Moreover, an (unsatisfactory) implicit assumption in the above relationship is that variables $x$ and $z$ are characterized by the same growth behaviour. In the next section, we check the validity of this assumption.

${ }^{3}$ Consistency requires that 'the short-run dynamic adjustment be directed by the perceived disequilibrium and that eventual convergence to the equilibrium position be ensured' [Salmon (1982), $p$. 615]. The equilibrium target path considers steady-state behaviour of the error (between the current and the target position) for different assumptions on the dynamic behaviour of the equilibrium value. Steadystate behaviour implies that the equilibrium value is consistent with any dynamic equilibrium path. For further technical discussion, see [Salmon (1982), pp. 616-620]. 
The above postulated steady-state is defined.as a proportional relationship between the nominal rupee exchange rate and the U. S. dollar per SDR exchange rate $(x)$ and domestic macro-economic variable $z$. This proportional relationship can be justified on the basis of the long-run rule-governed exchange rate regime. The justification for assuming the above steady-state relationship is that, in the short-run, there is scope for a discretionary-managed exchange rate policy. However, in the long-run, in order to steer the exchange rate towards its target path, the relationship between the short-run exchange rate and the target value, based on the policy objective, must be based on some kind of peg or rule-governed exchange rate regime.

Since the generalized floating of major currencies in 1973, the crucial issue for the exchange rate management policy is no longer between pegging or floating against a single currency or a basket of currencies, because either case involves accepting fluctuations against all other major international currencies. However, it is appropriate to make an important distinction between a rule-governed exchange rate regime and discretionary-managed exchange rate regime [Takagi (1986)]. Under a rule-governed regime, the value of the domestic currency with respect to the basket is automatically determined by the rules governing the operation of the basket. This regime is equivalent to a basket-peg, whereby the authorities give up control over the money supply in order to retain control over the exchange rate. In a discretionary-managed regime, the authorities take discretionary actions to adjust the value of the domestic currency with respect to the basket, and, thus, the authorities are able to retain some degree of monetary control. It is also possible for the authorities to make discrete adjustments in the composition of the basket in order to offset a loss of competitiveness or to reflect a change in the structure of the country's trade.

\section{2. Target Variables for Exchange Rate Management}

We now briefly highlight an aspect of the literature which, in the context of the LDCs, explores the desirable economic variable that could be the target of the exchange rate policy. Specifically, the aim of the subsequent discussion is to provide a perspective for the next section, where the behaviour of the SBP, with regard to the nominal exchange rate management, is modelled in order to 'reveal' the possible fundamental policy target variable. The policy objective may be defined in terms of the relative price variable (such as the terms of trade or the real exchange rate) or in terms of a macroeconomic variable (such as the balance of trade or the balance of payments).

Lipschitz (1979) argues that weights in the basket must be influenced by (a) the internal distribution of income and (b) the internal relative prices. Black (1976) 
suggested that the exchange rate adjustments should be made not only to achieve the internal and external balance but also to neutralise any inflation differential between the home country and its major trading partners. Similarly, Connolly (1980), based on the strict interpretation of the PPP, has argued for the minimization of the level and variance of differential inflation. Williamson (1987) also suggests frequent changes of the exchange rate in order to offset differential inflation, but advocates domestic or internal demand management policies to contain inflationary pressures rather than attempt to maintain a fixed nominal peg. Branson and Katseli (1981) derive weights for the currency basket when the exchange rate objective is the elimination of third country exchange rate fluctuations on the current account balance.

Finally, an important concern in the literature has been the contribution of relative price fluctuations to income instability. Mathieson and Mckinnon (1974) have suggested that the LDCs have generally experienced greater fluctuations in their real GNP than the DCs. Branson and Katseli (1980) showed that the terms of trade fluctuations are more significant in the case of the low per capita income countries (in the sense of appropriately weighted welfare loss from a given degree of instability) and, thus, constitute an important source of income instability, but the greater is the openness of the economy. Williamson (1982) has questioned the validity of pursuing the objective of stabilizing the terms of trade when such an approach involves countries having to reject potential windfall gains in order to improve their terms of trade in bad times.

The above discussion considered a menu of exchange rate policy objectives. In the next section, we test two of the possible long-run policy objectives being pursued by the authorities in Pakistan. However, in the short-run, an important concern is the operational management of the basket peg. Generally, the literature suggests a peg or a managed float to the SDR. It may be convenient that for shortterm adjustments, some composite daily movement of international currencies (SDR is one such example) is used as a peg. It is only after a certain time lag (primarily due to lags in data collection) that the authorities would want to steer the current exchange rate towards the equilibrium exchange rate value.

Williamson (1982) suggests that an SDR peg would have the following advantages: (a) Generally the SDR peg would produce less instability in the effective exchange rate than any single currency or some other composite index, such as the ECU; (b) the SDR peg will stabilize the cross rates against all other currencies that adopt the SDR as a peg; and (c) for homogeneous primary commodities, a basket representing world imports is more appropriate than the one which represents the exports of a particular country. Similarly, Takagi (1986) argues that pegging to the SDR is particularly attractive when the shares of the currencies that contribute to it reflect fairly closely a country's pattern of trade and payments. 


\section{LONG-RUN ADJUSTMENT MODELLING}

We now describe an adjustment process of the nominal rupee exchange rate. An econometric technique, based on an error correction mechanism (ECM), is employed to model the movement towards the long-run equilibrium rupee exchange rate path. As discussed in the previous section, an important question to consider is the consistency of the short-run adjustment given an equilibrium target path. We assume that the authorities are able to recognize deviations between the equilibrium value (on the target path) and the current position of the control variable, for any period. Any disturbance in the short-run adjustment process will then be transmitted through a dynamic reaction function (in our case, the ECM) on the observed disequilibrium.

The error correction mechanism (ECM) procedure adequately deals with the above phenomenon. The underlying idea is that when the observations begin to deviate from the steady-state path, the behaviour of the system can be captured by a reaction function. The ECM procedure defines an error correction term, whose effect is to check the divergent growth path of the dependent variable, by driving the variable to its long-run growth path.

The choice of variables for testing the order of integration is based on an initial attempt to explore the data by examining the consequences of modelling a simple dynamic adjustment process (not reported). In particular, we set-up two competing hypotheses; that the policy objective of nominal exchange rate management is either to offset (or neutralise) inflation differential between Pakistan and its major trading partners or the authorities are interested in stabilizing real national income. If, indeed, the former is the policy objective, then we expect the coefficient on relative inflation index ${ }^{4}$ to carry a negative sign. In the case of the latter policy objective, it would primarily require stabilization of the fluctuations in the terms of trade. Given Pakistan has net export-side market power, ${ }^{5}$ deterioration in the terms of trade can be offset by an increase in the (price of) rupee exchange rate. Accordingly, we expect the sign of the changes in the terms of trade variable to be positive.

The chosen estimation period is based on an examination of figures given in the appendix. On comparison of the two figures, one notices that the U. S. dollar

${ }^{4}$ Relative inflation index is a measure of the relative wholesale price index in Pakistan compared to the trade-weighted average of wholesale price indices of its major trading partners. The index base is January, 1982 and is calculated as a geometric average. Data source: NDFC Quarterly Review, (various issues) Karachi. I am limited by data availability to cover the entire estimation period.

${ }^{5}$ The calculations, by Branson and Katseli (1980), of market power indices for 101 countries suggest that Pakistan had net export-side market power for the year 1974. The conditions under which an improvement in terms of trade, consequent to depreciation of domestic currency, would actually take place are discussed in [Lindert and Kindleberger (1982); p. 297]. 
appreciated against the SDR upto March, 1985 (see Fig. 2). For this period, the rupee exchange rate against U. S. dollar depreciated almost continuously (see Fig. 1). After March, 1985, when the U. S. dollar started depreciating against the SDR, the parity rate exhibits a smooth and gradual depreciation of the rupee till the end of the estimation period (i.e., June, 1987). Therefore, the two phases of the U. S. dollar with respect to the rupee and the SDR will provide an opportunity to test for a structural break in the estimated dynamic reaction function. For economic implications of such a contingent policy rule, see [Williamson (1987), p. 41].

The choice of lags in estimated regressions has been solely dictated by the author's knowledge of the lags in collection and tabulation of relevant data in Pakistan and their subsequent availability to the authorities. The use of lags in various specifications is justified on the basis that, in order to follow the optimal exchange rate path, the authorities would want to immediately incorporate relevant information in a discretionary managed exchange rate regime. A strong test of our assertion would require that the estimated coefficients should accord with a priori signs.

\section{1. Integration and Co-integration}

In this section, we apply vector autoregression (VAR) to characterize the trend properties of the data. In a sense, VAR techniques are data-driven and no $a$ priori restriction from theory is imposed on the data. The first step in VAR is to establish whether each time-series contains a stochastic trend. The next step is to find out whether different time-series variables share a common stochastic trend, i.e., whether the comovement between the variables exists (in the long-run). The former is a test for the order of integration [i.e., I(d)-a series is integrated of order d] and the latter refers to the test for cointegration.

[Engle and Granger (1987), p. 252] and [Granger (1986), p. 214] define the requirement for integration of order zero $[\mathrm{I}(0)]$ as a (level) series whose spectrum is finite and non-zero at all frequencies. A series is integrated of order one [I(1)] if it must be differenced one time to be stationary. Stationarity implies that the first and second order moments of the process exist and are time-invariant, i.e., the form and parameters of the function do not vary through time [Granger and Watson (1984), p. 982]. [Engle and Granger (1987), p. 271; Hall (1986), p. 231 and Jenkinson (1986), p. 243] each provides motivation for various tests computed in Table 1 below.

To test for the order of integration, the Dickey-Fuller (DF) and Augmented Dickey-Fuller (ADF) tests are popularly employed. These tests are based on the OLS 'computed $t$-statistic'. This test-statistic does not have a $t$-distribution under the null, because of the theoretically infinite variance. The null hypothesis, say for 
Table 1

Tests for Integration

(January, 1983-June, 1987)

\section{A: Single Unit Root}

B: Second Unit Root

DF ADF

DF ADF $\mathrm{ADF}_{2}$

\begin{tabular}{lccccccccc} 
Series & $\beta_{0}$ & $\beta_{0}$ & DW & Series & $\beta_{1}$ & $\beta_{1}$ & $\beta_{1}$ & DW \\
\hline$y$ & 4.30 & 2.06 & 0.01 & $D y$ & -4.28 & -1.67 & -2.51 & 1.53 \\
$x$ & 2.08 & 0.20 & 0.03 & $D x$ & -4.85 & -1.52 & -2.40 & 1.38 \\
$z$ & 0.077 & 0.17 & 1.10 & $D z$ & -3.47 & -1.76 & -2.76 & 2.08 \\
$r i$ & 2.93 & 1.34 & 0.06 & Dri & -3.75 & -1.86 & -2.50 & 1.45 \\
\hline
\end{tabular}

Notes: 1. $y_{1}$ monthly time series represents U. S. \$ per Pakistani rupee; number of observations $=54$.

2. $x_{t}$ monthly time series represents U. S. $\$$ per SDR; number of observations $=54$.

3. $z_{t}$ quarterly time series represents Pak. external terms of trade; estimation period: Quarter 4, 1983-Quarter 2, 1987; number of observations $=15$. For Table $2, z_{1}$ is interpolated in order to obtain monthly data, where $w_{t-i}$ :changes in the external terms of trade (in domestic currency), lagged by $i$ month(s), i.e., $\ln \left(z / z_{t-1}\right)=w_{i}$. The above test statistic remain invariant on interpolated data.

4. $r i$ monthly time series represents Pak. relative inflation index (see Footnote 4); estimation period: April, 1983-June, 1986; number of observations $=39$.

5. DF (Dickey-Fuller) and ADF (Augmented Dickey-Fuller) tests. Say, for $y_{t}$ time series, the tests are computed as follows:

$$
\begin{aligned}
& D y_{t}=-\beta_{0} y_{t-1}+\sum_{j=1}^{p} \delta_{j} \cdot D y_{t-j}+e_{t} \text { (for single unit root) } \\
& D^{2} y_{t}=-\beta_{1} D y_{t-1}+\sum_{j=1}^{p} \delta_{j} \cdot D^{2} y_{t-j}+e_{t} \text { (for second unit root) }
\end{aligned}
$$

with $p=0$ for DF and $p=4$ for ADF tests, respectively, where $p$ is selected large enough to ensure that $e_{t}$ is empirically white noise. $\mathrm{ADF}_{2}$ is estimated for $p=2 . D$ is the difference operator. $D^{2} y_{t}$ is expanded as follows: $D^{2} y_{t}=y_{t}+y_{t-2}-2 y_{t-1}$.

6. Critical values for the DF and ADF tests at the 1 percent, 5 percent, and 10 percent significance levels, respectively, are -4.07 (DF), -3.37 (DF), and -3.03 (DF), and -3.77 (ADF), -3.17 (ADF), and -2.84 (ADF). Source: [Hall (1986), p. 233].

7. DW tests for a series integrated of order $I(0)$ and $I(1)$ are based on the following OLS regressions:

$$
\begin{array}{ll}
y_{t}=c+u_{t} & \mathrm{I}(0) \\
D y_{t}=c+u_{t} & \mathrm{I}(1)
\end{array}
$$

where $c$ is a constant. DW is the estimated Durbin-Watson statistic. Critical values (or limits) for the simple random walk, at 5 percent significance level, are 0.493 (for 51 observations), 0.770 (for 31 observations), 1.069 (for 21 observations), and 1.733 (for 11 observations). Source: [Sargan and Bhargava (1983), p. 157]. 
a variable $y_{t}$, is $H_{0}: y_{t} \sim(1)$, that is $y_{t}$, is not stationary in levels. The null is rejected if the computed $t$-statistic is negative and significantly different from zero. ${ }^{6}$ $\mathrm{ADF}_{2}$ is based on the [Engle and Granger (1987), pp. 268, 271] argument that it is appropriate to drop insignificant lags of the dependent variable in augmented tests.

[Jenkinson (1986), p. 243] points out that a drawback of the DF-based method is that the tests are not invariant to whether, under the null, the series is pure random walk or random walk with drift. The preferred test is based on the Sargan and Bhargava (1983) method. This test employs the standard DurbinWatson (DW) statistic, and is an invariant test against the alternative of a stationary first order autoregressive error process. Another reason for preferring the DW statistic is that the Sargan and Bhargava method allows the testing of significance based on a different number of observations; which is a particularly convenient test from the point of view of the present study. The explanatory notes for Table 1 below lay out the procedural methods for conducting various tests.

Table 1 presents test results of the hypothesis that the series $y_{t}, x_{t}, z_{t}$, and $r i$ might have up to two unit roots. The first block reports the results of the DF, ADF, and DW tests for a single unit root. In no case is there any evidence against the unit root hypothesis and the computed tests even have wrong signs. Thus, the null hypothesis that the series are stationary in levels has to be rejected. The second block shows the computed values for the $\mathrm{DF}, \mathrm{ADF}, \mathrm{ADF}_{2}$, and $\mathrm{DW}$ tests for a second unit root, i.e., for a unit root in the first difference of the series against the alternative that the series are stationary in first differences. According to the DF and DW tests, no series contains two unit roots, because all series have significant test statistics. Thus, the null hypothesis that the series are not stationary in first differences has to be rejected. However, the results of the augmented tests suggest that the above time series would achieve stationarity in second order differences. In other words, the above series are plausibly I(1) and further testing would produce I(2) [see below]. Nevertheless, the results do indicate that the above time series contains a stochastic trend over the estimated time period.

The next issue that we explore is whether the above series share a common stochastic trend. Testing for cointegration is to test for the long-term relatedness between time series that have, individually, a unit root. The Engle and Granger (1987) paper provides a rigorous treatment of the ideas underlying the following presentation. A more accessible reading, in terms of understanding the concepts, is Granger $(1986,1981)$. For a case of two variables, the variables are cointegrated of order one $[\mathrm{CI}(1,1)]$, if the two variables are individually $\mathrm{I}(1)$, but some linear

${ }^{6}$ The critical values, provided by [Engle and Granger (1987), p. 269], for DF-based tests are estimated by Monte Carlo simulation, using 10,000 replications for a series based on 100 observations. 
combination of the two is $\mathrm{I}(0){ }^{7}$ For example, we want to test whether a linear combination exists between variables $y_{t}$ and $x_{t}$, such that:

$$
u_{t}=y_{t}-\alpha x_{t}
$$

reduces the number of unit roots to produce mean-reverting 'equilibrium error' $u_{i}$. The term 'equilibrium' is used to describe the tendency of the endogenous variables to move towards a particular region of the possible outcome space, where a small value of $u_{t}$ is preferred to large values [Granger (1986), p. 216]. Testing for CI $(1,1)$ involves $u_{t}$ to be stationary and if $u_{t}$ follows $\mathrm{I}(0)$, then it can be concluded that a long-term equilibrium condition holds between $y_{t}$ and $x_{t}$ (i.e. $y_{t}-\alpha x_{t}=0$ ), except for a stationary disturbance term $u_{t}$ with a finite variance.

In order to test for $\mathrm{CI}$, the cointegration regressions are estimated by OLS (Table 2). A significant result established by Engle and Granger is that, in large samples, the OLS estimates for true value of cointegrating coefficient $\alpha$ are consistent and efficient. The null hypothesis of no $\mathrm{CI}$ is tested based on the cointegration regression Durbin-Watson statistic (CRDW), but testing whether CRDW is significantly greater than zero. An alternative is to perform the DF and ADF tests, based on the CI regression's estimated residuals $u_{i}$. All three tests are reported in Table 3.

Since the results of Table 1 did not provide a firm basis for deciding the order of integration, we proceeded to estimate the $\mathrm{CI}$ regressions in levels, and first differences for each pair of variables. Following the results of Tables 2 and 3, we find that cointegration is accepted between $D y_{1}$ and $D x_{1}$ (Equation 2, Table 2). All the parameter values are reasonable, test statistics are significant, and coefficients are correctly signed. Testing for CI between the second-order difference variables (i.e., $D^{2} y_{1}$ and $D^{2} x$ ) fails to be accepted because the absolute value on the coefficient of $u_{t-1}$ exceeds unity (Row 3, Table 3). Cointegration between $D y_{t}$ and $w_{1-3}$ (Equation 7, Table 2) fails to be accepted because of the incorrect sign. Although reported, we do not consider Equation 6 (Table 2) because the order of integration between the level variable $y_{t}$ and change variable $w_{t-3}$ is different and such $\mathrm{CI}$ regressions are meaningless [Granger (1986), p. 216].

However, in the trivariate specification between $D y_{t}, D x_{t}$, and $w$, Equation 11 (Table 2) parameters are correctly signed and the CRDW and DF tests reject the hypothesis of non-cointegration. The computed value of the ADF test statistic is quite close to the critical value. It is important to note that in Equation 9 (Table 2), the sign on the terms of trade variable is incorrect. This result highlights the significance of incorporating appropriate lags (i.e., lags in data collection and its avail-

${ }^{7}$ By a similar extension, when the variables are individually $I(2)$ and a linear combination of the two produces a series which is $I(1)$, the two variables are cointegrated of order two $[\mathrm{Cl}(2,2)]$. 
Table 2

Cointegrating Regressions: OLS Estimates

US\$/Rs vs US\$/SDR

1. $y_{t}=\begin{array}{r}-2.66 \\ (-151.70)\end{array}-\begin{array}{r}0.69 x_{1} \\ (-4.73)\end{array}$

0.29

2. $D y_{t}=-0.0068+0.410 D x_{t}$ $(-5.978)$ (4.943)

3. $D^{2} y_{1}=\underset{(-0.118)}{-0.0002}+\underset{(5.382)}{0.459 D^{2} x_{1}}$

US\$/Rs vs TOT $\left(w_{\imath}\right)$
4. $y_{t}$
$=\begin{array}{r}-2.72 \\ (-187.22)\end{array}$
$+\quad 0.22 w_{1}$
$-0.01$

5. $D y_{t}=\begin{gathered}-0.0055 \\ (4.03)\end{gathered}-\begin{aligned} & 0.0293 w_{t} \\ & (-1.05)\end{aligned}$

0.002

6. $y_{t}=\begin{array}{r}-2.727 \\ (-190.71)\end{array}+\frac{0.1488 w_{t-3}}{(0.5158)}$

7. $D y_{t}=\begin{gathered}-0.0056 \\ (-4.078)\end{gathered}-\begin{gathered}0.0177 w_{t-3} \\ (-0.634)\end{gathered}$

US\$/Rs, US\$/SDR, TOT $\left(w_{t}\right)$
8. $Y_{t}=\begin{gathered}-2.65 \\ (-155.18)\end{gathered}$
$-$
$\underset{(-5.151)}{0.752 x^{\prime}}+$
0.32

9. $D y_{t}=\underset{\substack{(-5.85) \\(-0067}}{-}$

$\begin{array}{cc}0.414 \mathrm{D} x_{t} & - \\ (5.03) & 0.033 w_{t} \\ (-1.42)\end{array}$

0.32

10. $y_{t}=\begin{array}{r}-2.666 \\ (-163.86)\end{array}-$
$0.714 x_{t}+0.286 w_{t-3}$ (1.228)




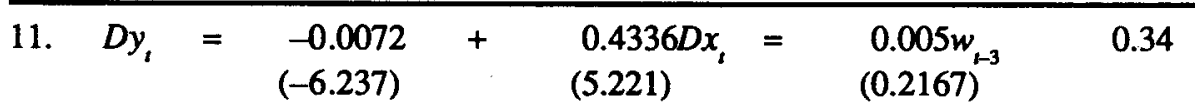

\section{US $\$ /$ Rs vs $r i$}

12. $y=$

$$
=\begin{gathered}
4.779 \\
(4.777)
\end{gathered}-\begin{gathered}
1.590 r_{t} \\
(-7.466)
\end{gathered}
$$

13. $D y_{t}=\underset{(-4.163)}{-0.0081}+\underset{(1.169)}{0.2288 \text { Dri }}$

14. $D^{2} y_{1}=\begin{gathered}-0.0005 \\ (-0.247)\end{gathered}-\begin{gathered}0.0700 D^{2} r i \\ (-0.350)\end{gathered}$

15. $y_{t}=\begin{gathered}4.553 \\ (4.153)\end{gathered}-\begin{gathered}1.544 r i_{1-2} \\ (-6.614)\end{gathered}$

16. $D y_{1}=\underset{(-4.215)}{-0.0083}+\underset{(1.597)}{0.311)^{-2}}$

17. $D^{2} y_{t}=\underset{(-0.189)}{-0.0004}+\underbrace{0.106 D^{2} r i_{1-2}}_{(0.536)}$

US\$/Rs, US\$/SDR, ri

18. $y_{i}=\begin{gathered}5.800 \\ (5.697)\end{gathered}+\begin{gathered}0.465 x_{t} \\ (2.529)\end{gathered}-\underset{(-8.332)}{1.812 r i} \quad 0.64$

19. $D y_{t}=\underset{(-5.937)}{-0.0089}+\underset{(5.145)}{0.508 D x_{t}}+\underset{(1.222)}{0.183 D r i}, 0.42$

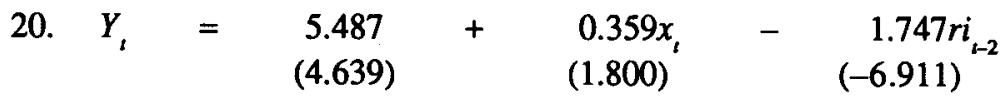

21. $D y_{t}=-0.0097+0.510 D x_{t}+$ $(-6.456)$ (5.307)

0.332 Dri $_{i-2}$

0.47

Notes: $1 . \bar{R}^{2}$ is the $R^{2}$ corrected for degrees of freedom.

2. $D$ is the first-order difference operator.

3. $D^{2}$ is the second-order difference operator.

4. Computed ' $t$ ' values in brackets. If pairs of variables are not $\mathrm{CI}$, then the estimates may be biased. 
Table 3

Tests for Cointegration

\begin{tabular}{llllll}
\hline & \multicolumn{2}{c}{$-\varnothing u_{t-1}$} & & \\
\cline { 3 - 6 } & DF & ADF & CRDW & DF & ADF \\
\hline US\$Rs vs US\$/SDR & & & & & \\
1. $\quad y_{t}, x_{t}$ & -0.06 & -0.06 & 0.038 & -2.02 & -2.01 \\
2. $D y_{t}, D x_{t}$ & -0.67 & -0.64 & 1.439 & -4.85 & -2.64 \\
3. $\quad D^{2} y_{t}, D^{2} x_{t}$ & -1.28 & -2.49 & 2.550 & -9.08 & -4.38
\end{tabular}

US\$/Rs vs TOT( $(w)$
4. $y_{t}, w_{t}$
$-0.01$
$-0.02$
0.018
$-0.59$
$-0.83$
5. $D y_{t}, w$,
$-0.71$
$-0.56$
1.535
$-5.20$
$-2.17$
6. $y_{t}, w_{t-3}$
$-0.006 \quad-0.01$
0.017
$-0.29$
$-0.56$
7. $D y_{t}, w_{t-3}$
$-0.71$
$-0.61$
1.453
$-5.00$
$-2.29$

US\$/Rs, US\$/SDR, TOT( $w$ )
8. $y_{t}, x_{t}, w_{t}$
$-0.08$
$-0.08$
0.089
$-1.98$
$-1.70$
9. $D y_{t}, D x_{t}, w_{1}$
$-0.79$
$-0.58$
1.464
$\begin{array}{ll}-6.04 & -2.37\end{array}$
10. $y_{t}, x_{t}, w_{t-3}$
$-0.06$
$-0.07$
0.076
$-1.39$
$-1.51$
11.

$$
D y_{t}, D x_{t}, w_{t-3}
$$
$-0.65$
$-0.70$
1.276
$-4.57 \quad-2.70$

US\$/Rs vs $r i$

12. $y_{i}, r i$

$-0.06$

$-0.14$

0.123

$-0.99$ $-2.32$ 
Table 3 - (Continued)

\begin{tabular}{lllllll}
\hline 13. & $D y_{t}, D r i$, & -0.74 & -0.67 & 1.367 & -4.25 & -1.87 \\
14. & $D^{2} y_{i}, D^{2} r i_{t}$ & -1.37 & -2.36 & 2.688 & -8.30 & -3.03 \\
15. & $y_{t}, r i_{t-2}$ & -0.06 & -0.12 & 0.125 & -1.08 & -2.00 \\
16. & $D y_{t}, r i_{t-2}$ & -0.78 & -0.73 & 1.494 & -4.33 & -1.97 \\
17. & $D^{2} y_{i}, D^{2} r i_{t-2}$ & -1.37 & -2.31 & 2.673 & -8.15 & -2.60
\end{tabular}

US\$/Rs, US\$/SDR, ri

\begin{tabular}{lllllll} 
18. & $y_{t}, x_{t}, r i$, & -0.07 & -0.12 & 0.148 & -1.16 & -1.70 \\
19. & $D y_{t}, D x_{t}, D r i$, & -0.66 & -0.62 & 1.401 & -3.90 & -1.72 \\
20. & $y_{t}, x_{t}, r i_{t-2}$ & -0.06 & -0.12 & 0.146 & -0.97 & -1.71 \\
21. & $D y_{t}, D x_{t}, D r i_{t-2}$ & -0.71 & -0.84 & 1.265 & -4.29 & -2.32 \\
\hline
\end{tabular}

Source: [Hall (1986), p. 233].

Notes: 1. $D F$ test: $D u_{t}=-\infty u_{t-1}+\varepsilon_{t}$ and

$A D F$ test: $D u_{t}=-ه u_{t-1}+\sum_{j=1}^{4} b_{j} D u_{t-j}+\varepsilon_{t}$, where $|\emptyset|<1$

2. Following are the critical values:

$1 \% \quad 5 \% \quad 10 \%$

2Variable case:

$\begin{array}{lccc}\text { CRDW } & 0.511 & 0.386 & 0.322 \\ \text { DF } & -4.07 & -3.37 & -3.03 \\ \text { ADF } & -3.77 & -3.17 & -2.84\end{array}$

3Variable case:

$\begin{array}{lccc}\text { CRDW } & 0.488 & 0.367 & 0.308 \\ \text { ADF } & -3.89 & -3.13 & -2.82 .\end{array}$


ability to the authorities) when formulating policy reaction functions. Therefore, it would seem reasonable to conclude that the three variables in Equation 11 (Table 2) constitute a cointegrating vector.

We now turn our attention to examine an alternative hypothesis of $\mathrm{CI}(1,1)$ between $y_{t}, x_{t}$, and the relative inflation differential variable $(r i)$. Both Equations 13 and 16 (Table 2) are correctly signed and the corresponding tests for $\mathrm{Cl}$ in Table 3 suggest a preference for Equation 16. However, an examination of the trivariate specifications (Equations 18-21, Table 2) strongly favours Equation 21, where the parameter values of the regression have reasonable values and are correctly signed. The CI tests (No. 21, Table 3) reject the null of non-cointegration and the computed value of $\mathrm{ADF}$ is fairly close to the critical value. Therefore, it seems reasonable to conclude that Equation 21 (Table 2) again constitutes a cointegrating vector.

The issue to consider is: Which of the above two possible conclusions can be judged to be correct? The approach adopted here is to apply time-tested $R^{2}$ and $t$ statistic criteria on Equations 11 and 21 (Table 2). On this basis, the trivariate case of cointegration between nominal rupee exchange rate, US\$/SDR, and relative inflation (first differenced: See Figures 3 and 4) variables is decisively accepted.

Before we leave this section, it is important to return and reconsider the issue of order of integration and order of cointegration, as applied on the present data set. On the basis of the VAR theory, variables are I(1) [see Table 1], while the results of CI tests suggest that variables are not $\mathrm{I}(0)$. Thus, the number of unit roots did not reduce to produce a mean-reverting equilibrium error. In other words, we failed to discover long-term relatedness between time-series variables. Various diagnostic tests were performed to check the appropriateness of the DF-test in Tables 1 and 3. For second unit root equation (see note 5, Table 1), the Breusch-Godfrey test [see Johnston (1984), p. 319] was conducted, for $\mathrm{p}=0$, to test whether $e_{i}^{\text {'s }}$ are in fact white noise. For each variable, the tests confirmed that the errors are non-autocorrelated and, therefore, the DF-test statistic can be validly compared to the critical values. Moving to Table 3, and concentrating on rows 18 and 20, we notice that the value of CRDW implies that the $A R(1)$ in $\varepsilon_{t}^{\prime}$ 's is of the order of 0.93 . At such levels, the power of the CRDW and DF tests becomes very low [for further elaboration, see Jenkinson (1986), pp. 244-245]. Therefore, an extension of the ADF was estimated (upto $\mathrm{p}=12$ ) with insignificant lagged dependent variables dropped in step-wise regressions. The overall results did not indicate any significant gain over the test values reported in Table 3. In the final stage, we examined the results of Table 3 with the critical values provided by [Engle and Yoo (1987), p. 157]. To test for CI, Engle and Yoo compute critical values for upto five variables and various sample sizes (the smallest sample size being 50). The comparison shows that the cointegration is accepted at 5 percent significance level (for Row 21, Table 3). Based on the Jenkinson (1986) approach, we proceed to employ error correction 
representation as an alternative test for cointegration (in first differenced variables).

\section{2. Error Correction Mechanism}

In the previous section, our endeavour was to achieve a suitable specification of the cointegrating equation. It is now possible to proceed to the second stage of the Engle and Granger procedure in order to estimate a valid ECM model of nominal rupee exchange rate. It was established by Engle and Granger (1987) that there always exists an error correcting specification of the dynamic model, if a set of variables are cointegrated. The underlying idea is to combine the long-run equilibrium relationship with the short-run dynamics of the model. Specifically, the aim is to model simultaneously the short-run dynamics (changes) and the long-run (levels) relationship, such that a dynamic adjustment to a steady-state target forms an ECM. An important implication of the Engle and Granger result is that it is possible to misspecify the dynamic structure of the model without affecting the consistency of the long-run estimates as implied from the estimated model.

Typically, the above is achieved by estimating a valid ECM, via the OLS, with the lagged residual of the cointegrated regression substituted for the error which is being corrected. We define $u_{t}$ to be the derived residuals from Equation 21 (Table 2). Since presumed cointegration was achieved in first differences (see Equation 21, Table 2), we proceed to formulate the ECM in terms of change of change variables (i.e., second-order differences). The ECM modelling strategy was to begin estimating an over-parameterised model with four lags on the dependent and independent variables. It is permissible to eliminate and restrict the influence of differenced variables until a parsimonious representation of the data generation process is obtained. The validation of this exercise is achieved by comparing the statistical properties of the restricted ECM with an estimated free ECM equation. The unrestricted (free) ECM includes the lagged values of the first-order differenced variables unrestrictedly (which defines the equilibrium solution of the model) in the dynamic specification of the restricted ECM. The results of the above exercise are tabulated in Table 4.

In Table 4, Equation (1) is one of the versions of the restricted ECM. An important finding from this equation is that the error-correction term $\left(u_{t-1}\right)$ and second-order relative inflation variable are significant, but the lagged dependent variable is insignificant and incorrectly signed. The corresponding unrestricted ECM specification is estimated as Equation (2). An examination of Equation (3) suggests that the inclusion of lagged dependent variables in the restricted ECM specification results in insignificant parameter estimates. Equation (4) suggests the significance of including the $D^{2} x_{t}$ variable. Therefore, the above equations were reparameterised and Equation (5) is a parsimonious representation of the data generation process [in comparison to Equations (1)/(2)]. The restricted ECM specifica- 
Table 4

An Error-correcting Model of Nominal Exchange Rate

\begin{tabular}{|c|c|c|c|c|c|c|}
\hline \multirow[b]{2}{*}{ Eq. No. } & \multicolumn{6}{|c|}{ Dependent Variable: $D^{2} y_{1}$} \\
\hline & (1) & (2) & (3) & (4) & (5) & (6) \\
\hline$c$ & $\begin{array}{l}-.0003 \\
(-.255)\end{array}$ & $\begin{array}{r}-.007 \\
(-2.95)\end{array}$ & $\begin{array}{l}-.0003 \\
(-.222)\end{array}$ & $\begin{array}{l}-.0003 \\
(-.13)\end{array}$ & $\begin{array}{l}-.0004 \\
(-.33)\end{array}$ & $\begin{array}{r}-.007 \\
(-3.03)\end{array}$ \\
\hline$D y_{t-1}$ & & $\begin{array}{r}-.701 \\
(-3.07)\end{array}$ & & & & $\begin{array}{c}-.613 \\
(-3.48)\end{array}$ \\
\hline$D x_{t-1}$ & & $\begin{array}{r}.311 \\
(1.83)\end{array}$ & & & & $\begin{array}{r}.263 \\
(1.75)\end{array}$ \\
\hline Dri $_{1-3}$ & & $\begin{array}{r}.331 \\
(1.74)\end{array}$ & & & & $\begin{array}{r}.317 \\
(1.70)\end{array}$ \\
\hline$u_{t-1}$ & $\begin{array}{r}-.705 \\
(-3.19)\end{array}$ & & $\begin{array}{r}-.773 \\
(-3.13)\end{array}$ & $\begin{array}{r}-.658 \\
(-1.91)\end{array}$ & $\begin{array}{r}-.605 \\
(-3.54)\end{array}$ & \\
\hline$D^{2} y_{t-1}$ & $\begin{array}{c}.141 \\
(.724)\end{array}$ & $\begin{array}{c}.126 \\
(.621)\end{array}$ & $\begin{array}{c}.186 \\
(.889)\end{array}$ & $\begin{array}{c}-.247 \\
(-.849)\end{array}$ & & \\
\hline$D^{2} y_{t-2}$ & & & $\begin{array}{c}.081 \\
(.645)\end{array}$ & & & \\
\hline$D^{2} x_{t}$ & $\begin{array}{r}.601 \\
(6.66)\end{array}$ & $\begin{array}{r}.583 \\
(5.53)\end{array}$ & $\begin{array}{c}.612 \\
(6.60)\end{array}$ & & $\begin{array}{r}.581 \\
(6.81)\end{array}$ & $\begin{array}{r}.565 \\
(5.64)\end{array}$ \\
\hline$D^{2} x_{t-1}$ & $\begin{array}{c}.067 \\
(.485)\end{array}$ & $\begin{array}{c}.095 \\
(.628)\end{array}$ & $\begin{array}{c}.078 \\
(.558)\end{array}$ & $\begin{array}{c}.062 \\
(.289)\end{array}$ & $\begin{array}{r}.145 \\
(1.70)\end{array}$ & $\begin{array}{r}.166 \\
(1.69)\end{array}$ \\
\hline$D^{2} r i_{t-2}$ & $\begin{array}{r}.288 \\
(2.34)\end{array}$ & $\begin{array}{r}.332 \\
(2.18)\end{array}$ & $\begin{array}{r}.297 \\
(2.37)\end{array}$ & $\begin{array}{c}.088 \\
(.469)\end{array}$ & $\begin{array}{r}.257 \\
(2.24)\end{array}$ & $\begin{array}{r}.312 \\
(2.12)\end{array}$ \\
\hline
\end{tabular}

Regression Statistics

$\begin{array}{lcccccc}R^{2} & 0.67 & 0.65 & 0.66 & 0.19 & 0.67 & 0.66 \\ F \text {-stat. } & 14.61 & 9.91 & 12.00 & 2.94 & 18.43 & 11.76 \\ D W & 2.03 & 2.04 & 1.96 & 1.97 & 1.99 & 2.00 \\ S E R & 0.007 & 0.008 & 0.007 & 0.012 & 0.007 & 0.008\end{array}$

Estimated $t$-statistic in brackets and number of observations $=35$ 
tion has correctly signed and significant variables (the absence of AR(1) is noted). Equation (5) has a high $R^{2}$ (corrected for degrees of freedom), while the standard error of regression (SERs) remains unaffected.

The absolute value of $u_{t-1}$ suggests the magnitude of the 'out-of-equilibrium' distance between the short-run nominal rupee exchange rate movement and the desired long-run target value of the authorities. In other words, $u_{1}$ is a stationary series and, thus, is inclined to move towards its mean value. A demanding test is to check for the constancy of parameter estimates of the restricted ECM specification (Chow test). ${ }^{8}$ The sample period was split at March, 1985 and derived residuals from the sub-sample cointegration regression were estimated. The restricted ECM for the sub-sample was re-estimated and the data accepted the null of parameter constancy at 5 percent significance level [computed $F$-statistic: $F_{(16,14)}=1.83$ ].

A powerful test of the restricted ECM specification is to study the effects of relaxing the coefficient restrictions as implied by the prior cointegrating regression (Equation 21, Table 2). The lagged values of the first-order differenced variables $y_{t}, x_{t}, r i_{t}-$ are estimated unrestrictedly in the dynamic specification (Equation 6 , Table 4). Almost all the variables are significant or nearly so (the absence of $A R(1)$ is noted). The parameter estimates of the second-order differenced variables of the restricted ECM and free ECM specifications are quite close. As a further test on Equation (6), we carried out the joint restriction test that the coefficients on lagged first differenced variables are zero [see Johnston (1984), p. 206 and Jenkinson (1986), p. 248]. The joint restriction was rejected by the $F$-test $\left[F_{(3,30)}=4.93>4.51\right.$ (critical value at 1 percent)]. This result lends credence to the conclusion of the previous section, namely, the cointegration between the variables in Equation 21 (Table 2).

The discussion so far can be summarised by examining the underlying relationship between the restricted ECM and the long-run solution implied from the previous section (Equation 21, Table 2). The above estimated ECM can be specified as follows (and ignoring the marginally significant $D^{2} x_{t-1}$ term):

$$
D^{2} y_{t}=-\tau u_{t}+\alpha D^{2} x_{t}+\beta D^{2} r i_{t-2}+\varepsilon_{t}
$$

${ }^{8}$ The following null hypothesis is tested (for $N_{1}>K$ ):

$H_{0}$ : B's are constant over the entire sample observations (i.e., $N$ months).

Under $H_{0}$, the Chow test for parameter stability is given by the following $F$-test statistic:

$$
\begin{aligned}
& \left\{\left(e^{\prime}{ }_{N}^{e}-e^{\prime}{ }_{N 1} e_{N 1}\right) /(N-N 1)\right\} /\left(\left(e^{\prime}{ }_{N 1} e_{N 1}\right) /(N 1-K)\right\} \\
& \approx F_{N-N 1} \cdot N 1-K .
\end{aligned}
$$


or

$$
D^{2} y_{t}=-\tau\left[D y_{t-1}-\alpha D x_{t-1}-\beta D r i_{t-3}\right]+\alpha D^{2} x_{t}+\beta D^{2} r i_{t-2}+\varepsilon_{t}
$$

Expanding the above equation and collecting terms, we obtain:

$$
D y_{t}=(1-\tau) D y_{t-1}+(\tau \alpha-\alpha) D x_{t-1}+(\tau \beta-\beta) D r i_{t-3}+\alpha D x_{t}+\beta D r i_{t-2}+\varepsilon_{t}
$$

Rearranging, we get the final equation:

$$
D y_{t}=\alpha D x_{t}+\beta D r i_{t-2}+(1-\tau)\left[D y_{t-1}-\alpha D x_{t-1}-\beta D r i_{t-3}\right]+\varepsilon_{t}
$$

In other words, Equation 21 (Table 2) contains much the same information about policy reaction function as the estimated ECM. It is also clear that the implied long-run equation contains an AR(1) error process (with $\tau=0.6$ ).

The above specification of the restricted ECM has satisfactorily achieved parameter constancy (and, thus, is valid for forecasting), the model is data coherent (the specification is representative of the data generation process), and the regressors are at least weakly exogenous (this requirement is necessary for testing hypotheses). In the words of [Gilbert (1986), p. 294], the parsimonious specification (Equation 5, Table 6) is congruent with the evidence that the authorities in Pakistan take the movements of the U. S. dollar vis-a-vis the SDR into account for the short-term determination of the nominal rupee exchange rate. In the long run, the policy objective of the authorities is to partially offset the relative inflation differential between Pakistan and its major trading partners. The above ECM specification forms a consistent dynamic policy reaction function, linking the short-run disequilibrium rupee exchange rate adjustment to the desired target path, based on the 'revealed' long-run policy objective of partly offsetting Pakistan's relative inflation differential.

In conclusion to this section, we can outline some of the economic consequences of not accommodating the inflation differential. Such a policy stance by the SBP would amount to an attempt to squeeze domestic inflation by allowing competitiveness to worsen. In the context of the Pakistani economy (and generally the LDCs), the realization of the above policy objective would hinge on the following two transmission mechanisms. First, since the Pakistani economy is quite dependent on the imports of industrial intermediate inputs as well as capital goods, the above policy would have a favourable impact on the cost matrix of the (mostly) import-substituting industrial sector. Second, firms producing exportables would find it necessary to control and reduce internal costs in order to remain price competitive. To the extent that the above is not achieved and the export demand price elasticity of (semi- and) manufactured goods is 'substantially' high, the effect of the above policy could well be a reduction in the output of the firms and a rise in 
internal costs. Ultimately, it might require exiting of firms and protracted recessionary conditions in the exportable sector in order to deliver the above policy aim.

Clearly, the 'revealed' exchange rate management policy objective is not compatible with the objective of export diversification, i.e., a shift from the exports of primary commodities to the exports of (semi- and) manufactured goods. Which of the above two transmission mechanisms will dominate and ensure the deliverance (or otherwise) of the above 'revealed' policy goal is an empirical question and an area for future research. However, in the context of the Pakistani economy, a question must be raised on the desirability of pursuing the above policy goal of partly offsetting the inflation differential, if the primary impetus to higher domestic inflation is directly linked to the 'high' budgetary deficits of the government. In recent years, the budget deficit in Pakistan has peaked to 8-9 percent of the GDP. In other words, if the inflation rate in Pakistan results from government choices, then a desirable policy goal and outcome could be to fully offset the relative inflation differential.

\section{CONCLUSIONS}

We would first discuss the limitations and possible extensions of this study. It needs to be established that Pakistan has net export-side market power based on 1974 data (see Footnote 5). An update of this calculation for recent years is necessary to justify the stabilization of terms of trade as a policy goal.

In Section II, the literature survey suggested that the basket weights have implications for the internal distribution of income and incentives/disincentives effects on resource allocation between non-traded goods, import-competing goods, and exportables. Similarly, it was also pointed out that different policy objectives have associated tradeoffs, and it is not desirable to consider policy objectives in isolation. Given the conclusion of this study, an obvious extension requires tracing the effects of 'revealed' policy objective on the above issues.

In this paper, we have not explicitly considered the optimal exchange rate policy objective, given the structural characteristics of the Pakistani economy. This study may be viewed as purely estimating empirical relationships, that is, the coefficients are not assumed to be estimates of parameters of an optimal exchange rate policy. Evidently, theoretical considerations suggested that explanatory variables be explored and their expected signs determined.

The introduction of the error correction mechanism (ECM) assumes that the authorities move the nominal exchange rate to its steady-state path in order to stabilize the changes in the relative price level variable. The application of the ECM procedure was justified due to its ability to check the explosive behaviour of simple dynamic specification. 
Underlying the estimated long-run relationship, the steady-state is postulated as a proportional relationship between the nominal rupee exchange rate and the $U$. S. dollar per SDR exchange rate and the domestic macro-economic variable. This proportional relationship can be justified on the basis of long-run rule-governed exchange rate regime. For the estimated period, the empirical estimate suggests that the error correction did not achieve about 0.6 percent of the desired target value of the authorities. Apparently, this refutes our assertion of the long-run rule-governed nominal exchange rate management. It is beyond the scope of this paper to judge whether the above empirical estimate is suggestive of a 'tolerable' level of (in)efficiency in exchange rate management.

Given the limited sample size and the nature of tenuous assumptions (see above), the tentative conclusion we offer is that in the short run, the authorities follow a contingent policy rule, i.e., discretionary management of the rupee exchange rate with regard to the movement in the U. S. dollar against the SDR. In the long run, the determinant of the nominal exchange rate policy objective is 'revealed' to partly offset the relative inflation differential. To the extent that the above is achieved, it provides the Pakistani exporters a partial compensation to loss in price competitiveness due to a higher domestic inflation. However, this paper does not establish the desirability of pursuing the above policy objective. Under certain plausible conditions (see conclusion of Section III. 2), the 'revealed' policy could induce recessionary conditions in the exportable sector. In the medium term, the effect of the policy could be a (further) worsening of the Pakistani trade balance. 


\section{APPENDIX}

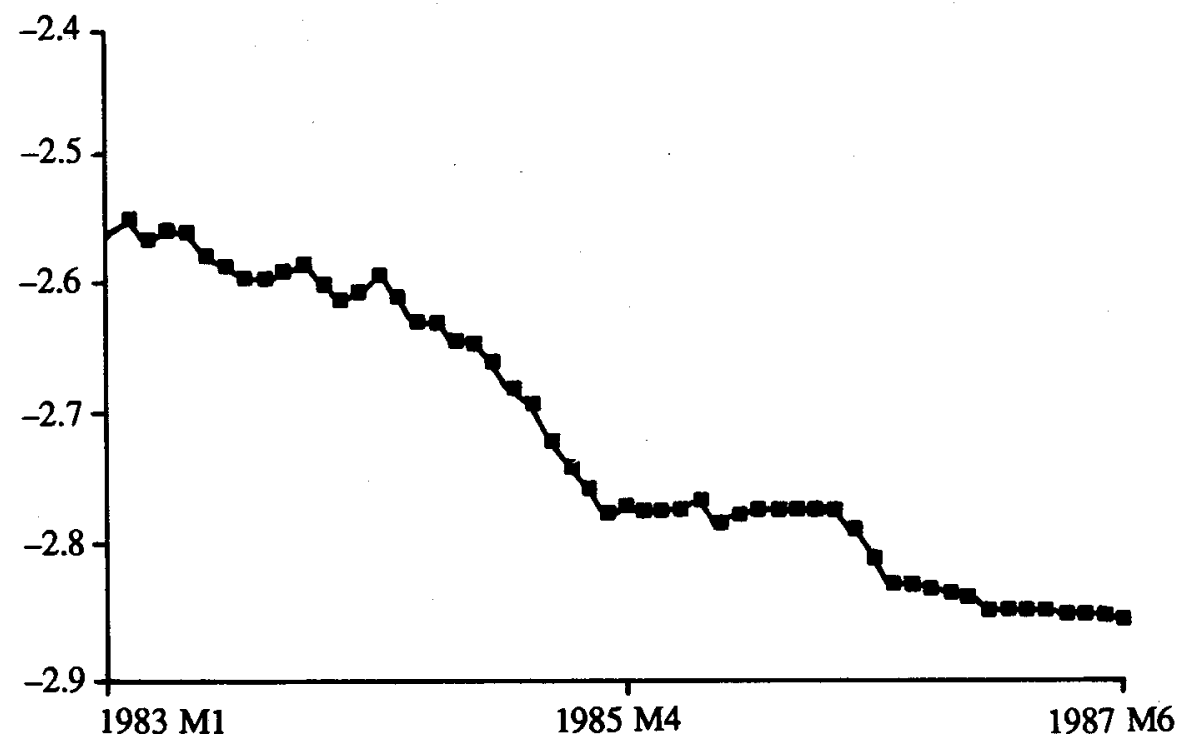

Fig. 1. U. S. dollar per Pak. Rupee $\left(Y_{t}\right)$.

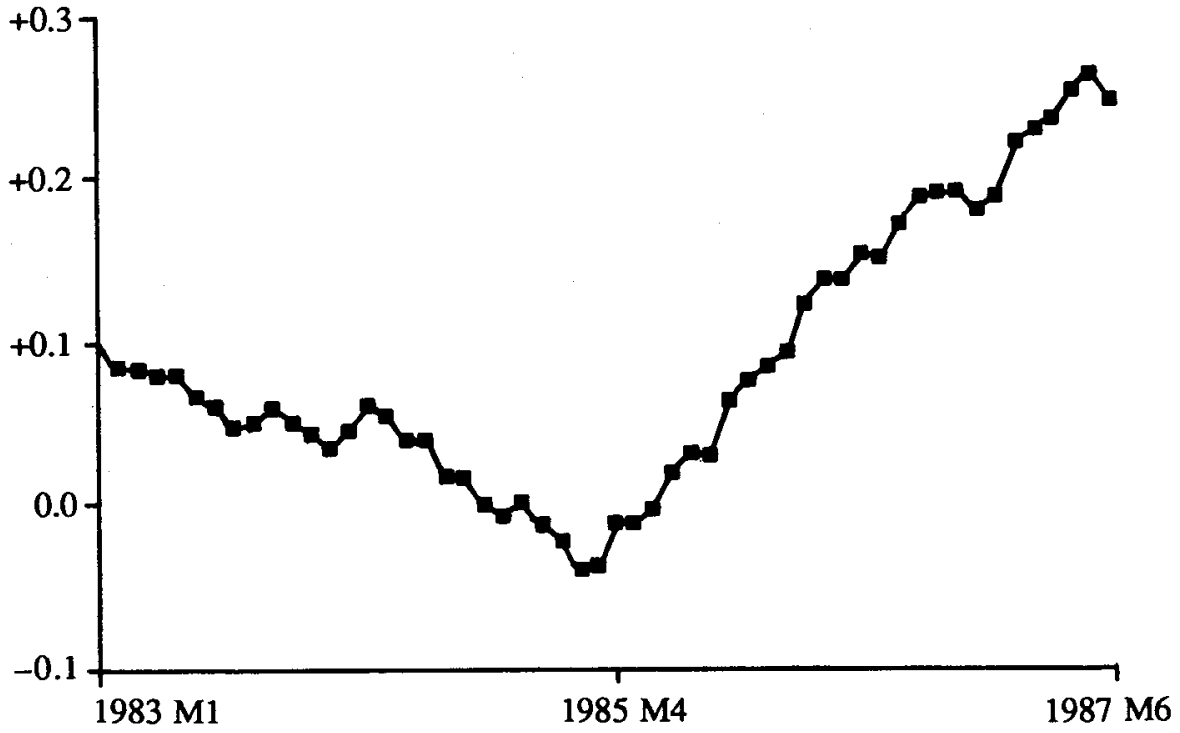

Fig. 2. U. S. dollar per SDR $\left(X_{t}\right)$. 


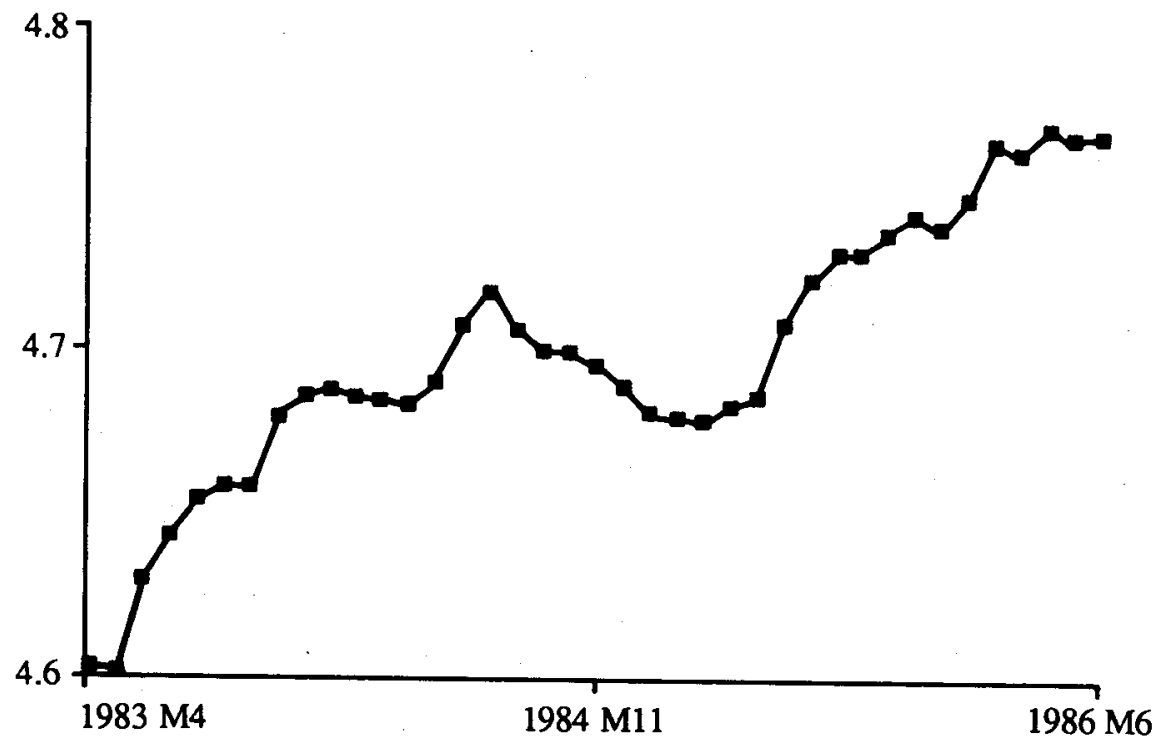

Fig. 3. Pakistan's Relative Inflation Index (Monthly Data).

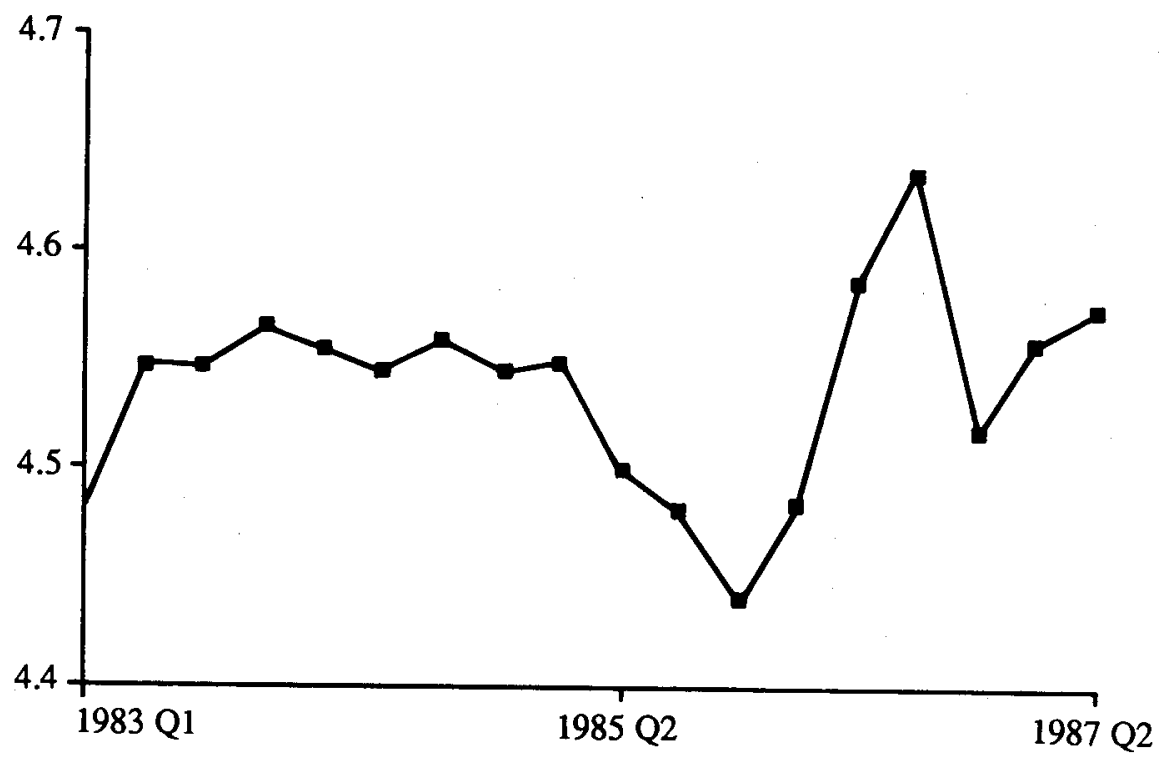

Fig. 4. Pakistan's Relative Inflation Index (Quarterly Data). 


\section{REFERENCES}

Black, S. W. (1976) Exchange Rate Policies for Less Developed Countries in a World of Floating Rates. Princeton Essays in International Finance. No. 119. Branson, W., and L. Katseli (1980) Income Instability, Terms of Trade, and the Choice of Exchange Rate Regime. Journal of Development Economics 7:1.

Branson, W., and L. Katseli (1981) Exchange Rate Policy for Developing Countries. In S. Grassman and E. Lundberg (eds) The World Economic Order: Past and Prospects.

Connolly, M. (1980) The Choice of an Optimum Currency Peg for a Small Open Economy. Columbia, USA.: Department of Economics, University of South Carolina. (Working Paper.)

Dornbusch, R. (1980) Open Economy Macroeconomics. 3rd Edition. New York: Basic Books.

Edwards, S. (1984) Real Exchange Rate Misalignment in Developing Countries: Analytical Issues and Empirical Evidence. Trade and Adjustment Policy

Division, The World Bank. (CPD Discussion Paper No. 1985-43)

Engle, R. F., and B. S. Yoo (1987) Forecasting and Testing in Co-Integrated Systems. Journal of Econometrics 35.

Engle; R. F., and C. W. J. Granger (1987) Co-integration and Error Correction: Representation, Estimation, and Testing. Econometrica 55:2.

Gilbert, C. L. (1986) Professor Hendry's Econometric Methodology. Oxford Bulletin of Economics and Statistics. Special Issue: Econometric Modelling with Cointegrated Variables 48:3.

Granger, C. W. (1981) Some Properties of Time Series Data and their Use in Econometric Model Specification. Journal of Econometrics 16.

Granger, C. W. (1986) Developments in the Study of Cointegrated Economic Variables. Oxford Bulletin of Economics and Statistics. Special Issue: Econometric Modelling with Coiṇtegrated Variables 48:3.

Granger, C. W. J., and M. W. Watson (1984) Time Series and Spectral Methods in Econometrics. In Z. Griliches and M. D. Intriligator (eds) Handbook of Econometrics II. The Netherlands: Elsevier Science Publishers B. V.

Gylfason, T. (1986) Does Devaluation Make Sense? Reprint Series No. 320. Sweden: Institute for International Economic Studies, University of Stockholm. Gylfason, T. (1987) Does Exchange Rate Policy Matter? Reprint Series No. 341. Sweden: Institute for International Economic Studies, University of Stockholm. Hall, S. G. (1986) An Application of the Engle and Granger Two-Step Estimation Procedure to United Kingdom Aggregate Wage Data. Oxford Bulletin of Economics and Statistics. Special Issue: Econometric Modelling with Cointegrated Variables 48:3. 
Jenkinson, T. J. (1986) Testing Neo-Classical Theories of Labour Demand: An Application of Cointegration Techniques. Oxford Bulletin of Economics and Statistics. Special Issue: Econometric Modelling with Cointegrated Variables 48:3

Johnston, J. (1984) Econometric Methods. 3rd Edition. Singapore: McGraw-Hill International Editions.

Lindert, P. H., and C. P. Kindleberger (1982) International Economics. 7th Edition. USA: Richard D. Irwin Inc.

Lipschitz, L. (1979) Exchange Rate Policy for a Small Developing Country, and the Selection of an Appropriate Standard. Washington, D. C. (IMF Staff Papers). Malik, M. M., and S. S. Rizavi (1982) A Note on the Estimation of Trade Weighted cum Inflation Adjusted Appreciation/Depreciation on the Pakistani Rupee. The Journal of Development Studies V.

Mathieson, D. J., and R. I. Mckinnon (1974) Instability in Underdeveloped Countries: The Impact of the International Economy. In P. David and M. Reder (eds) Nations and Households in Economic Growth.

Pagan, A. (1985) Time Series Behaviour and Dynamic Specification. Oxford Bulletin of Economics and Statistics 47:3.

Qureshi, M. L., and S. Nishat (1978) A Note on Trade-Weighted Over-Valuation of the Pakistani Rupee. The Pakistan Development Review 17:2.

Salmon, M. (1982) Error Correction Mechanisms. The Economic Journal 92: 615629.

Sargan, J. D., and A. Bhargava (1983) Testing Residuals from Least Squares Regression for Being Generated by the Gaussian Random Walk. Econometrica 51:1.

Takagi, S. (1986) Pegging to a Currency Basket. Finance and Development. The World Bank.

Williamson, J. (1982) A Survey of the Literature on the Optimal Peg. The Journal of Development Studies 11:1.

Williamson, J. (1987) Exchange Rate Policy for Developing Countries: A Case for Collective Action. Journal of Foreign Exchange and International Finance 1:1. Published by the National Institute of Bank Management, Pune, India. 